\title{
Determination of Direct Oral Anticoagulants from Human Serum Samples
}

\author{
Job Harenberg, MD, PhD ${ }^{1}$ Sandra Kraemer, BSc ${ }^{1} \quad$ Shanshan Du, MSc ${ }^{1}$ Christina Giese, FRBTech ${ }^{1}$ \\ Astrid Schulze, MD ${ }^{2}$ Roland Kraemer, PhD $^{3}$ Christel Weiss, PhD $^{4}$
}

1 Department of Clinical Pharmacology Mannheim, Medical Faculty Mannheim, University of Heidelberg, Mannheim, Germany

2 Department of Orthopedic and Trauma Surgery, Medical Faculty

Mannheim, University of Heidelberg, Mannheim, Germany

3 Inorganic Chemistry Institute, University of Heidelberg,

Heidelberg, Germany

${ }^{4}$ Department of Biometry and Statistics, Medical Faculty Mannheim, University of Heidelberg, Mannheim, Germany
Address for correspondence Job Harenberg, MD, PhD, Department of Clinical Pharmacology Manheim, Medical Faculty Mannheim, University of Heidelberg, Maybachstrasse. 14, 68169 Mannheim, Germany (e-mail: job.harenberg@medma.uni-heidelberg.de).

\begin{abstract}
Keywords

- direct oral anticoagulants

- dabigatran

- rivaroxaban

- apixaban

- serum

- methods

Dabigatran, rivaroxaban, and apixaban are direct oral anticoagulants (DOAC) inhibiting thrombin or factor $\mathrm{Xa}$ and effectively preventing thromboembolic complications using fixed doses without need for laboratory-guided dose adjustment. Plasma samples are needed to determine the actual concentration or activity of DOACs, which may be required for special patient populations such as those with acute deterioration of renal function due to any disease, before surgical interventions, during bleeding or thrombotic episodes while on therapy with DOACs, the elderly and youngest populations, unexpected pregnancy, suspicion of overdose and toxication, and to control adherence to therapy. Serum samples have several advantages over plasma samples such as no need of sampling with a specific coagulation tube, reduced pre-analytical errors, and longer storage stability. Determination of rivaroxaban and apixaban from serum samples of patients on treatment performed well and better than samples of patients treated with dabigatran compared with plasma samples. Specific adaption to automated coagulation platforms may improve the performance of the assays from serum samples.
\end{abstract}

Serum samples are taken from all patients in acute and nonacute clinical situations. On adequate handling, clinical chemical analyses are performed on automated clinical chemistry analyzers. Blood coagulation parameters need to be collected into plastic or siliconized glass tubes containing an anticoagulant such as sodium citrate to inhibit blood coagulation in vitro. Limitations of blood drawing for coagulation parameters include incomplete filling of the tube resulting in an incorrect ratio of anticoagulant to blood leading to incorrect coagulation results and activation of blood clotting during and after blood sampling due to incorrect handling. Correct handling and centrifugation at given temperatures, analysis within a given time frame, and specific caution for freezing and thawing of samples are also required. ${ }^{1}$

Serum samples of patients are often used to determine the concentration of drugs during therapy. ${ }^{2}$ Drug levels or other clinical chemical parameters may be requested by clinicians hours or days after original blood collection as an add on test. Therefore, serum samples are frequently stored routinely for several days. This becomes important for patients with drug overdose or intoxication or for forensic purposes. ${ }^{3,4}$ Heparin, low-molecular-weight heparin, fondaparinux, and danaparoid need antithrombin or heparin-cofactor II for accelerating
Issue Theme Hot Topics V; Guest Editor, Emmanuel J. Favaloro, PhD, FFSc (RCPA). published online December 31, 2013
DOI http://dx.doi.org/ 10.1055/s-0033-1363462. ISSN 0094-6176.
Copyright (c) 2014 by Thieme Medical Publishers, Inc., 333 Seventh Avenue, New York, NY 10001, USA. Tel: +1(212) 584-4662.
License terms

(요 $\Theta \circledast$ 
the inhibition of specific coagulation enzymes. ${ }^{5}$ A specific determination of hirudins requires activation through meizothrombin. ${ }^{6}$ Antithrombin and meizothrombin are consumed during blood clotting as would take place during preparation of serum. Therefore, antithrombin and meizothrombin-dependent anticoagulant drugs may encounter limitations when analyzed from serum samples.

DOACs bind specifically either to thrombin or to factor Xa. These coagulation proteases are also consumed during blood clotting that occurs during preparation of serum samples. DOAC concentrations are determined by liquid chromatography techniques after extensive purification from plasma proteins. ${ }^{7-9}$ These methods require specialized techniques and expert operators, which are rarely available in routine laboratories. UV (ultraviolet)-detection photometry analysis provides an easy, less time consuming, and sensitive analysis for pharmaceuticals. Here, we describe a simple and rapid photometric method for the determination of DOAC in serum. We have compared data obtained by spiking DOAC to human serum and plasma samples as well as from patients on treatment.

\section{Methods}

\section{Patients}

These studies were approved by the local ethics committee and participants gave written informed consent before blood sampling. Serum and plasma samples were taken from patients under treatment with rivaroxaban 10-mg once daily before and between days 4 to 6 following primary elective total knee and hip replacement surgery 12 hours after intake of medicine, from patients with atrial fibrillation on treatment with dabigatran 110 - or 150 -mg twice daily ( 2 or 12 hours after intake of medicine) or treated with apixaban 5-mg twice daily 12 hours after intake of the drug and for control studies from patients not taking any anticoagulant.

\section{Preparation of Samples}

\section{Serum Samples}

Blood was collected from control persons without intake of an anticoagulant and from patients on treatment with one of the DOACs into kaolin containing plastic tubes to generate and obtain serum. Blood was allowed to clot at room temperature for 30 minutes. Samples were centrifuged at $1,800 \mathrm{~g}$ and room temperature for 10 minutes and the supernatant was shock frozen in aliquots and stored at $-72^{\circ} \mathrm{C}$ until analyzed.

\section{Plasma Samples}

Blood for platelet poor plasma (PPP) samples were taken during the same venipuncture as for those to obtain serum, collected into plastic tubes containing $3.8 \%$ sodium citrate $(1 / 9, \mathrm{v} / \mathrm{v}$, citrate/ blood), centrifuged within 30 minutes at $1,800 \mathrm{~g}$ and room temperature for 10 minutes and several aliquots of the supernatant were shock frozen and kept at $-85^{\circ} \mathrm{C}$ until analyzed.

\section{Origin and Quality of DOACs}

Dabigatran and rivaroxaban were purified from commercially available Pradaxa (Boehringer, Ingelheim, Germany) and
Xarelto (Bayer HealthCare, Wuppertal, Germany; optical density at $405 \mathrm{~nm}$ ) and their purity was characterized by analytical methods as described. ${ }^{10,11}$ Apixaban was provided by BMS (Plainsboro, $\mathrm{NJ}$ ).

\section{Spiking of Serum and Plasma Samples with DOAC}

Serial dilutions of dabigatran, rivaroxaban, and apixaban were added to 6 (rivaroxaban and apixaban) or 4 (dabigatran) individual serum and plasma samples from persons not taking an anticoagulant. Samples were analyzed within 2 hours for the content of the DOAC by the methods described later. The mean of the six determinations was calculated for serum and plasma samples of each DOAC. The concentration of each sample was calculated from the optical density at $405 \mathrm{~nm}$ (OD) concentration curve for serum and plasma samples of each DOAC using SAS release 9.3 program (SAS Institute Inc., Cary, NC).

\section{Analysis of Dabigatran}

\section{Serum Samples}

Dabigatran was determined from serum samples by a colorimetric method ${ }^{12}$ (international patent application No PCT/ EP2012/002540). The assays were run on a microtiter plate reader with duplicate samples (Multiskan FC, Thermo Fisher Scientific, Langenselbold, Germany) connected to the software program SkanIt 3.1 (Thermo Fisher Scientific, Germany). Initially, the assay was developed by using different amounts of the reagents and incubation periods (data not shown). The final assay procedure was as initially described also for plasma samples. ${ }^{13}$ Ten $\mu \mathrm{L}$ serum and $100 \mu \mathrm{L}$ tris buffer $(0.05 \mathrm{~mol}$ Tris, $0.075 \mathrm{~mol} \mathrm{EDTA}, 0.175 \mathrm{~mol} \mathrm{NaCl}, 37 \mathrm{KIU}$ aprotinin/mL, pH 8.4) were incubated for 5 minutes followed by addition of $100 \mu \mathrm{L}$ human thrombin (Sigma Aldrich, Deisenhofen, Germany, 0.74 $\mathrm{NIH}$ units/mL tris buffer), for 60 seconds at $37^{\circ} \mathrm{C}$. Fifty $\mu \mathrm{L}$ chromogenic substrate $\mathrm{S} 2238$ (1.59 $\mathrm{mmol} / \mathrm{L}$ in distilled water, Chromogenix, Essen, Germany) were added and incubated for 5 minutes. The reaction was stopped by adding $25 \mu \mathrm{L} 20 \%$ acetic acid. For all samples, a background OD at $405 \mathrm{~nm}$ was used by pipetting the reagents from backward, that is, first acetic acid, to ensure a similar final matrix but with no activity. Absorption of samples was read at $405 \mathrm{~nm}$ and the concentration of dabigatran of the samples was calculated from a concentration/optical density curve using the software program and prepared from pooled human serum samples (obtained from 20 volunteers) spiked with dabigatran ranging from 25 to $500 \mathrm{ng} / \mathrm{mL}$.

\section{Plasma Samples}

The assay was performed with the same solution and incubation steps as for serum samples using the software program SkanIt 3.1 for Multiskan FC.

\section{Analysis of Rivaroxaban and Apixaban}

Serum Samples

Rivaroxaban and apixaban were determined by a colorimetric method $^{14}$ in the presence of human factor Xa and a substrate (patent No GB1019674.9). The samples and reagents were 
pipetted into microtiter plates and after a special time period the results of the reaction were measured in a special reader (Multiskan FC, Thermo Fisher Scientific, Langenselbold, Germany) connected to the software program SkanIt 3.1 (Thermo Fisher Scientific, Germany).

The optimal assay conditions were developed using serial dilutions of the reagents and incubation times (data not shown). The final assay was conducted as follows: $25 \mu \mathrm{L}$ serum (diluted $1: 15$ with tris-buffer) and $25 \mu \mathrm{L}$ factor Xa (7.1 nkat $/ \mathrm{mL})$ were incubated for 2 minutes followed by addition of $50 \mu \mathrm{L}$ chromogenic substrate S2222 (3.37 mmol/L distilled water, Chromogenix, Essen, Germany). After 20 minutes of incubation, the reaction was stopped by adding $25 \mu \mathrm{L}$ of $20 \%$ acetic acid. For all samples, a background OD at $405 \mathrm{~nm}$ was used by pipetting the reagents from backward, that is, first acetic acid. Absorption of samples was read at $405 \mathrm{~nm}$ and the concentration of rivaroxaban/apixaban of the samples was calculated from a concentration/optical density curve prepared from pooled human serum samples (obtained from 20 volunteers) spiked with rivaroxaban/apixaban using the software program.

\section{Plasma Samples}

The antifactor Xa activity was performed with the same assay conditions as described for serum samples to determine rivaroxaban/apixaban and using the software program SkanIt 3.1 for Multiskan FC.

\section{Statistical Analysis}

Data are given as mean and standard deviation (SD). Box plots were used for the figures of concentration of DOAC in serum and plasma samples. Differences between groups were calculated using the SAS release 9.3 software program. SAS mixed procedure was used to analyze differences between control and patients groups. The level of significance was determined by the npar one-way procedure. The level of significance was set at $p<0.01$.

\section{Results}

\section{Spiking of DOAC to Serum and Plasma Samples}

Spiking of serial dilutions of the DOAC showed no differences for serum and plasma concentrations for dabigatran $(r=0.9997)$, rivaroxaban $(r=0.9991)$, and apixaban $(r=0.9998)$, respectively ( - Fig. 1A-C).

\section{Patients on Treatment with Dabigatran}

Patients not on treatment with an anticoagulant displayed serum and plasma concentrations of $16.6 \pm 18.7 \mathrm{ng} / \mathrm{mL}$ and $8.4 \pm 7.7 \mathrm{ng} / \mathrm{mL}$, respectively $(p=0.0001$ ) (-Fig. 2A). In patients on therapy, the concentrations of dabigatran in serum $(n=219)$ and plasma $(n=363)$ were $75.9 \pm 70.2 \mathrm{ng} / \mathrm{mL}$ and $112.9 \pm 85.8 \mathrm{ng} / \mathrm{mL}$, respectively $(p=0.0223)$ ( - Fig. 2B). The $p$ values for differences of serum samples of control versus patients was 0.0085 and for plasma samples less than 0.0001 . The correlation of serum and plasma values was $r=0.165$.
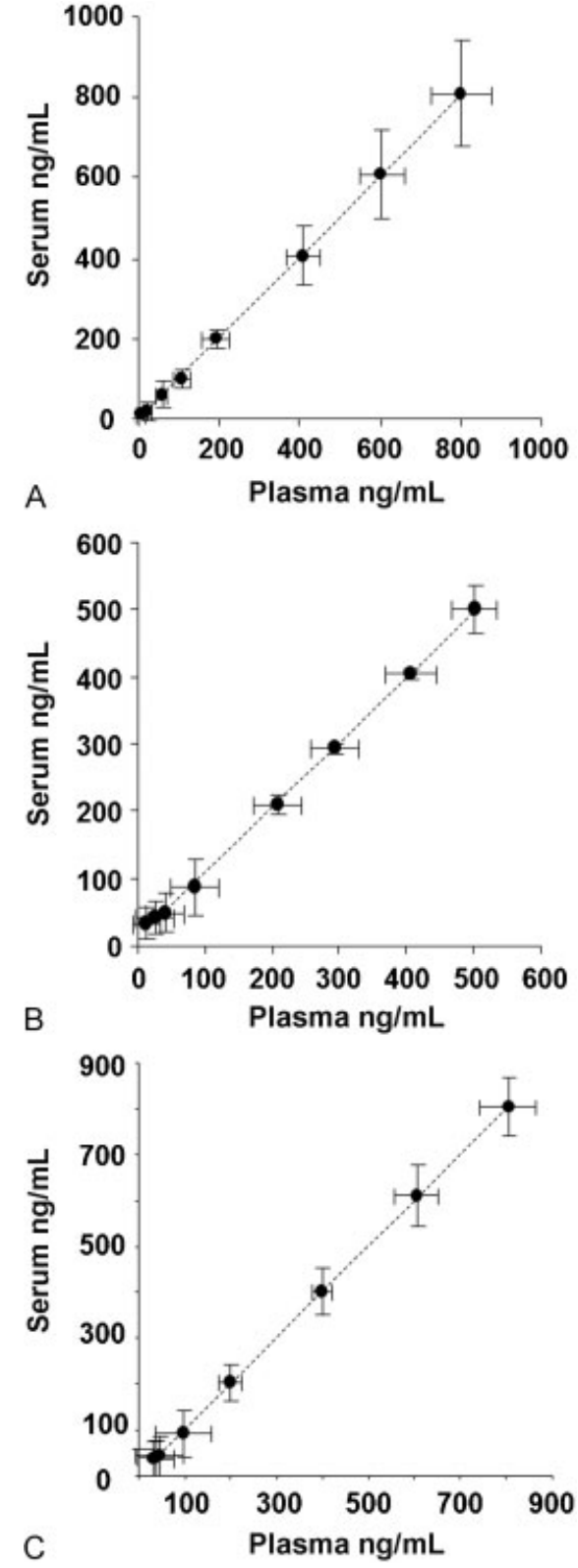

Fig. 1 Comparative concentrations of direct oral anticoagulants (DOACs) for serum and plasma samples of healthy volunteers $(n=6$, mean, SD) spiked with different concentrations of dabigatran (A), rivaroxaban (B), and apixaban (C), as measured by test procedure described in text and OD at $405 \mathrm{~nm}$.

\section{Patients on Treatment with Rivaroxaban}

Control patients without intake of an anticoagulant had serum $(n=143)$ and plasma $(n=144)$ concentrations for rivaroxaban of $18.0 \pm 17.6 \mathrm{ng} / \mathrm{mL}$ and $14.5 \pm 12.4 \mathrm{ng} / \mathrm{mL}$ respectively $(p=0.36)$ ( - Fig. $3 \mathbf{A}$ ). In patients on therapy, the concentrations of rivaroxaban in serum $(n=132)$ and plasma $(n=135)$ were $81.7 \pm 40.3 \mathrm{ng} / \mathrm{mL}$ and $66.5 \pm 40.7$ respectively ( $p=0.0003$ ) ( - Fig. 3B). The $p$ values for differences of serum and plasma samples of controls versus patients were both less than 0.0001 . Values of serum and plasma samples displayed a correlation of 0.7251 . 


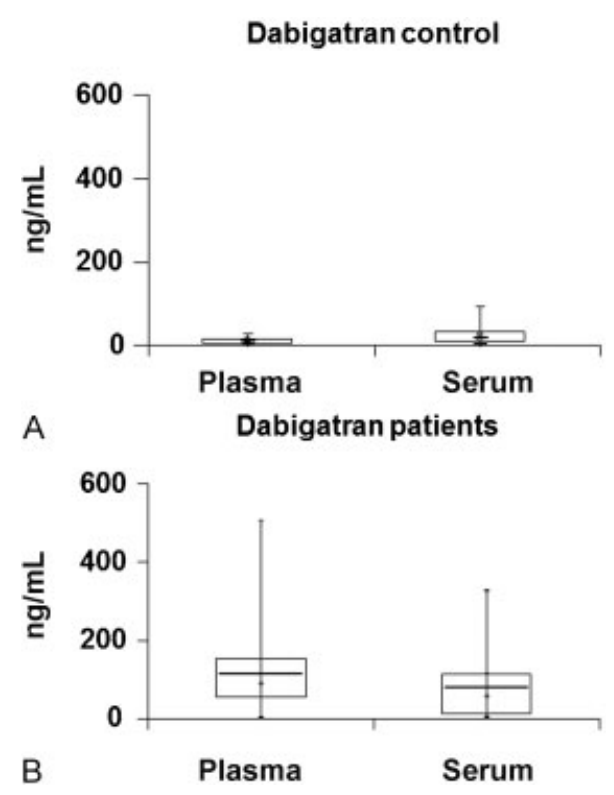

Fig. 2 Box plots of concentrations of dabigatran in serum and plasma samples of control persons not treated with an anticoagulant $(A)$, and on treatment with dabigatran (B).

\section{Patients on Treatment with Apixaban}

Control patients without intake of an anticoagulant had serum $(n=48)$ and plasma $(n=48)$ concentrations for apixaban of $24.4 \pm 18.1 \mathrm{ng} / \mathrm{mL}$ and $16.8 \pm 23.2 \mathrm{ng} / \mathrm{mL}$,

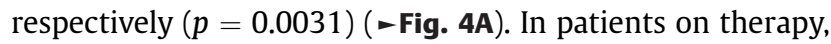
the concentrations of apixaban in serum $(n=58)$ and plasma $(n=69)$ were $263.6 \pm 141.7 \mathrm{ng} / \mathrm{mL}$ and $190.7 \pm 82.4$ respec-

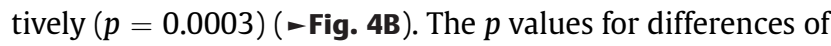
serum and plasma samples of controls versus patients were both less than 0.0001 . The correlation of serum and plasma values in patients was $r=0.709$.

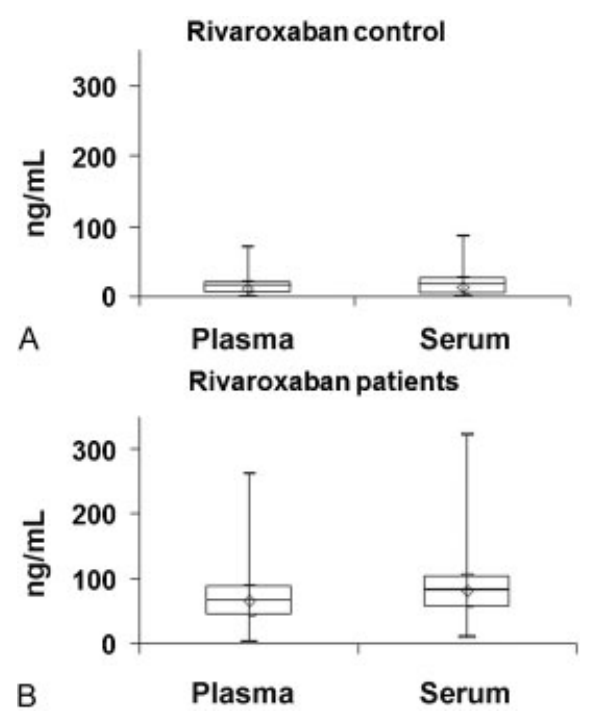

Fig. 3 Box plots of concentrations of rivaroxaban in serum and plasma samples of control persons not treated with an anticoagulant $(A)$ and of patients on therapy with rivaroxaban (B).

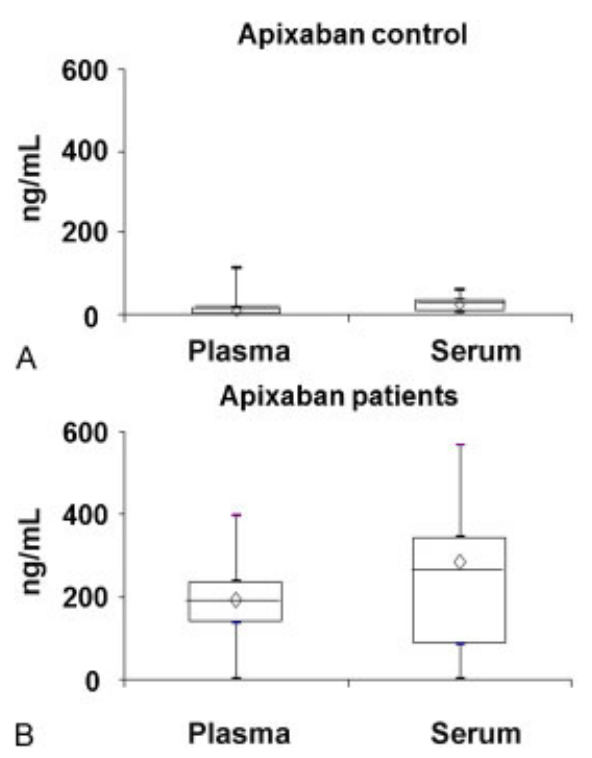

Fig. 4 Box plots of concentrations of apixaban in serum and plasma samples of control persons not treated with an anticoagulant $(A)$ and of patients treated with apixaban (B).

\section{Discussion}

The results of the present investigations demonstrate that dabigatran, rivaroxaban, and apixaban can be determined from serum samples after spiking samples with the DAOC. The correlations of serum and plasma samples were very high and in the same range as reported for other drugs. ${ }^{15}$ The correlation of values using serum and plasma samples of patients on treatment was lower but also in the range reported for other drugs. ${ }^{16}$ Dabigatran showed lower relation between serum and plasma levels using samples of patients on treatment compared with rivaroxaban or apixaban. Instability of drugs in serum has been reported for other compounds. ${ }^{17}$ The reason of a higher variability of serum compared with plasma concentrations of patients on treatment with the thrombin inhibitor dabigatran may be manifold and remain to be investigated.

Methods for determination of drugs in serum samples are required if plasma samples are not available (3). Serum samples are preferred for determination of drugs because of the absence of many proteins that relates mainly to coagulation proteins. Purification of drugs from serum samples is therefore easier to perform. ${ }^{18}$ DOACs can also be the determined from serum samples using sophisticated liquid chromatography techniques $(7,8,9)$. With these analyses, we demonstrated that DOACs can be determined also by adding an excess of thrombin or factor Xa followed by addition of an enzyme-specific substrate that releases quantitatively a chromophor from the substrate negatively related to the presence of the DOAC $(12,14)$. These assays can be performed in laboratories equipped with coagulation platforms to determine anticoagulants.

Clinical trials with DOACs were performed without determination of the anticoagulant effect of dabigatran, ${ }^{19}$ rivaroxaban $^{20}$ or apixaban. ${ }^{21}$ Pharmacokinetic analyses were 
computed using a population-based model for dabiga$\operatorname{tran}^{22,23}$ and rivaroxaban. ${ }^{24-26}$ Markers for activation of blood coagulation were reported from a clinical study using apixaban. ${ }^{27}$ Few reports were published for small patient groups treated with dabigatran ${ }^{28-30}$ or rivaroxaban. ${ }^{29,31-33}$ The reported values for subjects not on DOACs are in the same range as reported in our patients using plasma and serum samples. For apixaban, similar ranges of steady state plasma concentrations were reported for volunteers as in our patients. $^{34}$

There were some differences between the results of the three DOACs when determined in serum and in plasma samples from patients on treatment. For dabigatran, control values were higher in serum than in plasma samples. In patients, however, dabigatran concentrations were lower in serum than in plasma samples. However, differences were significant between persons not on dabigatran and patients on treatment in both cases. Therefore, patients on treatment can be separated from control values using serum samples as well as plasma samples. One reason for the lower values in serum samples of patients on treatment may that dabigatran is consumed during coagulation of blood after withdrawal to obtain serum. This may explain in part also the low correlation of serum and plasma values in patients on therapy with dabigatran. The mechanism of fibrin formation in serum samples in the presence of dabigatran remains to be investigated.

Values for controls without treatment of rivaroxaban were not different but somewhat higher for apixaban in serum compared with plasma samples. In patients on treatment, serum values were higher for rivaroxaban and apixaban when determined from serum samples compared with plasma samples. The mechanisms of the interaction of these inhibitors on fibrin formation and the difference to dabigatran remain to be determined. Importantly, serum samples are significantly higher in patients on therapy compared with controls and serum and plasma concentrations show a good correlation.

The amount of anticoagulant present in patient may be necessary to be determined in deterioration of renal function, in the elderly or oldest population, for surgery or in acute clinical situations, during recurrent events or during bleeding complications, or to check compliance. ${ }^{35,36}$ The concentration of DOACs can be accurately determined by high-pressure liquid chromatography methods. These techniques are, however, not suitable for clinical routine use. Thrombin- and factor Xa-dependent coagulation or chromogenic substrate assays are developed to determine the concentration or activity of dabigatran, rivaroxaban, and apixaban.

The limitations of this investigation are that the determination DOAC in serum samples remains to be validated in clinical studies. However, a validation of the plasma concentrations of DOACs also has to be undertaken in relation to the incidences of thrombotic or bleeding events. The time of blood sampling after the intake of the last dose of the anticoagulant plays an important role and remains to be standardized in general. The strength of the investigations is that the feasibility of using serum samples for the determination of DOACs was shown using a simple and reliable method that can be applied to a coagulation platform connected with a photometer.

In conclusion, the determination of dabigatran, rivaroxaban, and apixaban from serum samples of patients may offer an additional tool in specific clinical situations such as lack of withdrawal of plasma samples or facilitated freezing compared with plasma. The suitability of the determination of DOACs from serum samples by other anti-factor Xa chromogenic substrate assays remains to be proven. If this results in positive findings, adaption of the assays to specific coagulation platforms may reduce the variability of the results. ${ }^{37}$

\section{Acknowledgment}

The research was supported by a grant of the Dietmar Hopp foundation. We thank Antje Hagedorn and Inge Träger for providing technical assistance.

\section{References}

1 Lippi G, Salvagno GL, Montagnana M, Lima-Oliveira G, Guidi GC, Favaloro EJ. Quality standards for sample collection in coagulation testing. Semin Thromb Hemost 2012;38(6):565-575

2 Juenke JM, Brown PI, Urry FM, Johnson-Davis KL, McMillin GA. Simultaneous UPLC-MS/MS assay for the detection of the traditional antipsychotics haloperidol, fluphenazine, perphenazine, and thiothixene in serum and plasma. Clin Chim Acta 2013;423(1):32-34

3 Wu AH, McKay C, Broussard LA, et al; National Academy of Clinical Biochemistry Laboratory Medicine. National academy of clinical biochemistry laboratory medicine practice guidelines: recommendations for the use of laboratory tests to support poisoned patients who present to the emergency department. Clin Chem 2003;49(3):357-379

4 Bush DM. The U.S. Mandatory Guidelines for Federal Workplace Drug Testing Programs: current status and future considerations. Forensic Sci Int 2008;174(2-3):111-119

5 Gray E, Hogwood J, Mulloy B. The anticoagulant and antithrombotic mechanisms of heparin. Handbook Exp Pharmacol 2012; 207(207):43-61

6 Fischer BE, Schlokat U, Himmelspach M, Dorner F. Binding of hirudin to meizothrombin. Protein Eng 1998;11(8):715-721

7 Hu ZY, Parker RB, Herring VL, Laizure SC. Conventional liquid chromatography/triple quadrupole mass spectrometry based metabolite identification and semi-quantitative estimation approach in the investigation of in vitro dabigatran etexilate metabolism. Anal Bioanal Chem 2013;405(5):1695-1704

8 Rohde G. Determination of rivaroxaban-a novel, oral, direct Factor Xa inhibitor-in human plasma by high-performance liquid chromatography-tandem mass spectrometry. J Chromatogr B Analyt Technol Biomed Life Sci 2008;872(1-2):43-50

9 He K, Luettgen JM, Zhang D, et al. Preclinical pharmacokinetics and pharmacodynamics of apixaban, a potent and selective factor Xa inhibitor. Eur J Drug Metab Pharmacokinet 2011;36(3): 129-139

10 Harenberg J, Giese C, Marx S, Krämer R. Determination of dabigatran in human plasma samples. Semin Thromb Hemost 2012; 38(1):16-22

11 Harenberg J, Marx S, Weiss C, Krämer R, Samama M, Schulman S; Subcommittee on Control of Anticoagulation of the ISTH. Report of the Subcommittee of Control of Anticoagulation on the determination of the anticoagulant effects of rivaroxaban. J Thromb Haemost 2012;10(7):1433-1436

12 Harenberg J, Kraemer R. Direct thrombin inhibitors. International patent application No PCT/EP2012/002540. 2012 
13 Gray E, Harenberg J; ISTH Control of Anticoagulation SSC Working Group on Thrombin Inhibitors. Collaborative study on monitoring methods to determine direct thrombin inhibitors lepirudin and argatroban. J Thromb Haemost 2005;3(9):2096-2097

14 Harenberg J, Kraemer R. Direct factor Xa inhibitors. International Patent Application PCT/EP2011/005586. 2011

15 Marin SJ, Roberts M, Wood M, McMillin GA. Sensitive UPLC-MS-MS assay for 21 benzodiazepine drugs and metabolites, zolpidem and zopiclone in serum or plasma. J Anal Toxicol 2012;36(7):472-476

16 Couchman L, Birch M, Ireland R, et al. An automated method for the measurement of a range of tyrosine kinase inhibitors in human plasma or serum using turbulent flow liquid chromatography-tandem mass spectrometry. Anal Bioanal Chem 2012;403(6):1685-1695

17 Theurillat R, Sendi P, Thormann W. An MEKC assay for the therapeutic drug monitoring of cefepime. J Sep Sci 2013;36(17): 2915-2921

18 Olives AI, González-Ruiz V, Martín MA. Isolation and quantitative methods for analysis of non-steroidal anti-inflammatory drugs. Antiinflamm Antiallergy Agents Med Chem 2012;11(1):65-95

19 Connolly SJ, Ezekowitz MD, Yusuf S, et al; RE-LY Steering Committee and Investigators. Dabigatran versus warfarin in patients with atrial fibrillation. N Engl J Med 2009;361(12):1139-1151

20 Patel MR, Mahaffey KW, Garg J, et al; ROCKET AF Investigators. Rivaroxaban versus warfarin in nonvalvular atrial fibrillation. $\mathrm{N}$ Engl J Med 2011;365(10):883-891

21 Granger CB, Alexander JH, McMurray JJ, et al; ARISTOTLE Committees and Investigators. Apixaban versus warfarin in patients with atrial fibrillation. N Engl J Med 2011;365(11):981-992

22 Liesenfeld KH, Schäfer HG, Trocóniz IF, Tillmann C, Eriksson BI, Stangier J. Effects of the direct thrombin inhibitor dabigatran on ex vivo coagulation time in orthopaedic surgery patients: a population model analysis. Br J Clin Pharmacol 2006;62(5):527-537

23 Clemens A, Haertter S, Friedman J, et al. Twice daily dosing of dabigatran for stroke prevention in atrial fibrillation: a pharmacokinetic justification. Curr Med Res Opin 2012;28(2):195-201

24 Mueck W, Borris LC, Dahl OE, et al. Population pharmacokinetics and pharmacodynamics of once- and twice-daily rivaroxaban for the prevention of venous thromboembolism in patients undergoing total hip replacement. Thromb Haemost 2008;100(3): 453-461

25 Mueck W, Lensing AW, Agnelli G, Decousus H, Prandoni P, Misselwitz F. Rivaroxaban: population pharmacokinetic analyses in patients treated for acute deep-vein thrombosis and exposure simulations in patients with atrial fibrillation treated for stroke prevention. Clin Pharmacokinet 2011;50(10):675-686
26 Tanigawa T, Kaneko M, Hashizume K, et al. Model-based dose selection for phase III rivaroxaban study in Japanese patients with non-valvular atrial fibrillation. Drug Metab Pharmacokinet 2013; 28(1):59-70

27 Becker RC, Alexander JH, Newby LK, et al. Effect of apixaban, an oral and direct factor Xa inhibitor, on coagulation activity biomarkers following acute coronary syndrome. Thromb Haemost 2010; 104(5):976-983

28 Harenberg J, Giese C, Marx S, Krämer R. Determination of dabigatran in human plasma samples. Semin Thromb Hemost 2012; 38(1):16-22

29 Samama MM, Guinet C, Le Flem L, Ninin E, Debue JM. Measurement of dabigatran and rivaroxaban in primary prevention of venous thromboembolism in 106 patients, who have undergone major orthopedic surgery: an observational study. J Thromb Thrombolysis 2013;35(2):140-146

30 Hapgood G, Butler J, Malan E, Chunilal S, Tran H. The effect of dabigatran on the activated partial thromboplastin time and thrombin time as determined by the Hemoclot thrombin inhibitor assay in patient plasma samples. Thromb Haemost 2013;110(2): 308-315

31 Harenberg J, Erdle S, Marx S, Krämer R. Determination of rivaroxaban in human plasma samples. Semin Thromb Hemost 2012; 38(2):178-184

32 Douxfils J, Tamigniau A, Chatelain B, et al. Comparison of calibrated chromogenic anti-Xa assay and PT tests with LC-MS/MS for the therapeutic monitoring of patients treated with rivaroxaban. Thromb Haemost 2013;110(4):723-731

33 Mueck W, Schwers S, Stampfuss J. Rivaroxaban and other novel oral anticoagulants: pharmacokinetics in healthy subjects, specific patient populations and relevance of coagulation monitoring. Thromb J 2013;11(1):10

34 Frost C, Nepal S, Wang J, et al. Safety, pharmacokinetics and pharmacodynamics of multiple oral doses of apixaban, a factor Xa inhibitor, in healthy subjects. Br J Clin Pharmacol 2013;76(5): 776-786

35 Mismetti P, Laporte S. New oral antithrombotics: a need for laboratory monitoring. For. J Thromb Haemost 2010;8(4): 621-626

36 Harenberg J, Marx S, Erdle S, Krämer R. Determination of the anticoagulant effects of new oral anticoagulants: an unmet need. Expert Rev Hematol 2012;5(1):107-113

37 Nagler M, Bachmann LM, Alberio L, et al. Variability between laboratories performing coagulation tests with identical platforms: a nationwide evaluation study. Thromb J 2013;11(1):6 